\title{
Knowledge and Practice of Seat Belt Use among Pregnant Women
}

\author{
1,2 Suzanna Daud, ${ }^{2}$ Akmal ZM Zahid, ${ }^{1,2}$ Bahiyah Abdullah, ${ }^{3}$ Mariam Mohamad
}

\begin{abstract}
Aim: Our study aims to determine the prevalence of seatbelt use in pregnancy and associated factors of the correct seat belt use.

Materials and methods: This is a cross-sectional survey of the pregnant women who presented to the antenatal clinic of a tertiary medical center for 12 months. Patients were selected by using a systematic random sampling method. Face-to-face interview by trained interviewers was done to collect data, based on 11 questions survey. Participants' knowledge on correct placement of both the lap and shoulder belt was assessed using a representative diagram.
\end{abstract}

Results: Eighty pregnant women participated in the interview. Their mean age was $30( \pm 3.85)$ years old, $76.3 \%$ of them attained post-secondary school education, and the majority $(68.8 \%)$ was multigravida. Only $20(25 \%)$ women knew the correct use of the seatbelt. There were no significant associations between knowing the correct use of seatbelt with the women's age $(p=0.18)$, educational level $(p=0.10)$, gravidity $(p=0.21)$, gestation $(p=0.44)$ and status of ever receive information on seatbelt usage $(p=0.07)$. The highest source of information was from printed materials

A total of $66(82.5 \%)$ women drove during pregnancy and 74 $(92.5 \%)$ were passengers. Six of the participants were neither a driver nor a passenger as they were public transport users. More than half $(57.6 \%)$ of the drivers will always use a seatbelt, but only $43.2 \%$ will always use a seatbelt when they were passengers. More than $80 \%$ of those who did not always wear a seatbelt either as drivers or passengers stated feeling uncomfortable as a reason for noncompliance.

Conclusion: There is lacking in awareness of the importance and correct seat belt use in pregnancy among the pregnant women. Steps should be taken to increase the correct usage of seatbelts to reduce maternal and fetal mortality due to road traffic accidents.

Keywords: Accident, Antenatal, Car, Car restraint, Pregnancy, Seat belt.

How to cite this article: Daud S, Zahid AZM, Abdullah B, Mohamad M. Knowledge and Practice of Seat Belt Use among Pregnant Women. J South Asian Feder Obst Gynae 2018;10(Suppl 1):297-301.

\section{Source of support: Nil}

Conflict of interest: None

\footnotetext{
${ }^{1}$ Associate Professor, ${ }^{2,3}$ Senior Lecturer

${ }^{1}$ Maternofetal and Embryo (MatE) Research Group, Universiti Teknologi MARA (UiTM), Sungai Buloh, Selangor, Malaysia

2Department of Obstetrics and Gynaecology, Faculty of Medicine, Universiti Teknologi MARA Sungai Buloh, Selangor, Malaysia

${ }^{3}$ Department of Population Health and Preventative Medicine, Universiti Teknologi MARA (UiTM) Sungai Buloh, Selangor, Malaysia

Corresponding Author: Suzanna Daud, Associate Professor, Department of Obstetrics and Gynaecology, Faculty of Medicine, Universiti Teknologi MARA Sungai Buloh, Selangor, Malaysia, e-mail: suzannadaud@hotmail.com
}

Date of received: 8 August 2016

Date of acceptance: 1 May 2018

Date of publication: July 2019

\section{INTRODUCTION}

Road traffic accidents continue to be a major contributor to worldwide morbidity and mortality. ${ }^{1}$

About $1.5-3.8 \%$ of road traffic accidents involving pregnant women ${ }^{2}$ and up to $3 \%$ of pregnant women experience crashes during pregnancy. ${ }^{3}$ It has been shown that wearing a seat belt correctly can save lives. The previous study has shown that the mortality rate in pregnant women not wearing a seat belt is double that of those not using one. ${ }^{4}$ Pregnant women who were thrown from the car in road traffic accidents, may the interior object of the vehicle or the pavement once ejected. Therefore the mortality rate for those who were ejected from the vehicle was $33 \%$ compared to $5 \%$ who were not ejected. The adoption of the three-point seat belt has managed to reduce the death rate by $45 \%$ and moderate critical injuries by $50 \%{ }^{5}$ This is reflected in current legislation in some countries, which make their use compulsory.

Road traffic accidents are the leading cause of fetal death associated with maternal trauma ${ }^{6}$, mainly due to the death of pregnant women. ${ }^{4}$ When the mother was ejected from the car, the fetal mortality was $47 \%$ compared to $11 \%$ when the mother remained in the car. Studies also found that there is a reduction in risk of experiencing adverse fetal outcomes when a pregnant woman uses a seat belt properly. ${ }^{7,8}$ Fetal survival was improved if a three-point seat belt usage rather than a lap belt alone was worn. ${ }^{4,9}$ Seat belt worn inappropriately has been reported to cause harm. ${ }^{10}$

Despite their demonstrated effectiveness, the use of seat belt varies widely. One report in the United Kingdom revealed that only $13 \%$ of pregnant women wear their seat belt in the correct position as prescribed by the National Highway Traffic Safety Administration (NHTSA) guidance. Other study found incorrect placement rate of $52 \%$ during pregnancy. ${ }^{11}$ Further, Hammond et al. ${ }^{12}$ found only $77.6 \%$ of interviewed wore the seat belt correctly.

It has been shown that, if pregnant women were involved in a road traffic accident, they are likely to be in the car as a passenger or a driver, rather than to be a bicyclist or 
pedestrian struck by a car as compared to the nonpregnant women. ${ }^{2}$ Therefore, it is important for us to study the use of a seat belt in the pregnant woman. This study aims to determine the prevalence of seat belt use in pregnancy and associated factors of the correct seat belt use.

\section{MATERIALS AND METHODS}

This is a cross-sectional survey of the pregnant women who presented to the antenatal clinic of a tertiary medical center from July 2015 until August 2015. Sample size estimation for this study was calculated based on the published data by Acar et al., ${ }^{13}$ who reported the prevalence of seat belt usage during pregnancy was 13\%. By taking alpha $=0.05$ and $80 \%$ power of the study, using OpenEpi software, the sample size estimation was 80 .

Patients were selected by using a systematic random sampling method and were given information sheets, and informed consent was taken from those who volunteer to participate. Data was collected by face to face interview by trained interviewers based on 11 questions survey. The questionnaire includes inquiries on the frequency of seat belt use in pregnancy either as a driver or a passenger, the reason of not using a seat belt (if applicable), whether the advice was given pertaining to seat belt practice in pregnancy and source of information. Participants knowledge on correct placement of both the lap and shoulder belt was assessed using a representative diagram.
The data were entered and analyzed using the statistical package for social science version 20.0 (SPSS Inc, Chicago, IL). Descriptive data were presented in the form of absolute number and percentage while inferential statistics were calculated using independent $\mathrm{t}$-test and chi-square with significance level taken at 0.05 .

\section{Ethical and Humane Considerations}

Ethical approval was obtained from the Universiti Teknologi MARA (UiTM) Ethics Committee (Reference no. REC/111/15).

\section{RESULTS}

Eighty pregnant women participated in the interview. Their mean age was $30( \pm 3.85)$ years old, $76.3 \%$ of them attained postsecondary school education, and the majority (68.8\%) was multigravida. Only 20 (25\%) women knew the correct use of the seat belt. There were no significant associations between knowing the correct use of seat belt with the women's age $(p=0.18)$, educational level $(p=0.10)$, gravidity $(p=0.21)$, gestation $(p=0.44)$ and status of ever received information on seat belt usage $(p=0.07)$. The highest source of information was from printed materials (Table 1).

A total of 66 (82.5\%) women drove during pregnancy and $74(92.5 \%)$ were passengers. Six of the participants were neither a driver nor a passenger as they were public transport users. More than half $(57.6 \%)$ of the drivers will

Table 1: Factors associated with the correct use of seat belt during pregnancy and source of information on seat belt use

\begin{tabular}{|c|c|c|c|c|c|c|c|}
\hline & \multirow{2}{*}{$\begin{array}{l}\text { Total } \\
(n=80) \\
n(\%)\end{array}$} & \multicolumn{2}{|c|}{ Correct use $(n=20)$} & \multicolumn{2}{|c|}{ Wrong use $(n=60)$} & \multirow[t]{2}{*}{$X_{2}(d f)$} & \multirow[t]{2}{*}{$p$ value } \\
\hline & & $n$ & $\%$ & $n$ & $\%$ & & \\
\hline \multicolumn{8}{|l|}{ Education level } \\
\hline Primary/secondary & $19(23.8)$ & 5 & 25.0 & 14 & 23.3 & $0.23(1)$ & 0.10 \\
\hline Postsecondary & $61(76.3)$ & 15 & 75.0 & 46 & 76.7 & & \\
\hline \multicolumn{8}{|l|}{ Gravidity } \\
\hline Multigravida & $55(68.8)$ & 16 & 80.0 & 39 & 65.0 & & \\
\hline \multicolumn{8}{|l|}{ Gestation } \\
\hline First/second trimester & $38(47.5)$ & 11 & 55.0 & 27 & 45.0 & $0.60(1)$ & 0.44 \\
\hline Third trimester & $42(52.5)$ & 9 & 45.0 & 33 & 55.0 & & \\
\hline \multicolumn{8}{|l|}{ Received information } \\
\hline Yes & $20(25)$ & 8 & 40.0 & 12 & 20.0 & $3.20(1)$ & 0.07 \\
\hline Mean age (years) & $30.3 \pm 3.85$ & $31.3 \pm 3.9$ & & $29.9 \pm 4.1$ & & $1.35^{*}(78)$ & 0.18 \\
\hline $\begin{array}{l}\text { Source of information } \\
\text { (multiple responses) }\end{array}$ & $(n=20)$ & & & & & & \\
\hline Friends and relatives & $8(24.2)$ & & & & & & \\
\hline Healthcare personnel & $4(12.1)$ & & & & & & \\
\hline Mass media & $7(21.2)$ & & & & & & \\
\hline Printed material & $11(33.3)$ & & & & & & \\
\hline Others & $3(9.1)$ & & & & & & \\
\hline Total response & 33 & & & & & & \\
\hline
\end{tabular}

*Independent t-test 
Table 2: Practice of seat belt use among women who drive $(n=66)$ and as a passenger $(n=74)$

\begin{tabular}{lll}
\hline & $\begin{array}{l}\text { As a driver, } \\
(\%) \\
(n=66)\end{array}$ & $\begin{array}{l}\text { As a } \\
\text { passenger, } \\
n(\%) \\
(n=74)\end{array}$ \\
\hline $\begin{array}{l}\text { Driving frequency } \\
\text { Everyday or almost everyday }\end{array}$ & $\begin{array}{l}47(71.2) \\
\text { A few days a week }\end{array}$ & $31(41.9)$ \\
A few days a month & $5(21.2)$ & $35(47.3)$ \\
Use of seat belt & & $8(10.8)$ \\
Always (100\%) & $38(57.6)$ & $32(43.2)$ \\
Usually (>75\%) & $6(9.1)$ & $17(23.0)$ \\
Sometimes (50-74\%) & $14(21.2)$ & $11(14.9)$ \\
Rarely (25-49\%) & $4(6.1)$ & $6(8.1)$ \\
Never (<25\%) & $4(6.1)$ & $8(10.8)$ \\
Reasons for lack of seat belt use & $(\mathrm{n}=28)$ & $(\mathrm{n}=42)$ \\
Uncomfortable/inconvenience & $24(85.7)$ & $34(81.0)$ \\
Not necessary for safety in a & $4(14.3)$ & $8(19.0)$ \\
short trip & & \\
\hline
\end{tabular}

always use a seat belt, but only $43.2 \%$ will always use a seat belt when they were passengers. More than $80 \%$ of those who did not always wear a seat belt either as drivers or passengers stated feeling uncomfortable as a reason for noncompliance (Table 2).

\section{DISCUSSION}

It has been a known fact that the use of a seat belt is able to reduce death and critical injury caused by road traffic accidents. This is applicable for the general public including the pregnant women. Alarmingly, our study found low compliance of seat belt use among pregnant women when traveling in a motor vehicle as either a driver or a passenger. Among those who drove $(n=66$, $83 \%$ ), self-reported compliance to seat belt use is $57.6 \%$. The low compliance to the seat belt use is worrying as it has been shown that the majority of pregnant women who involved in motor vehicle accident were seated in the front seats, as the driver or the front passenger. ${ }^{8}$ There was a wide range of rates of compliance on seat belt use as a driver has been reported in previous studies, ranging from $49-98 \% .{ }^{14-16}$ In addition, this study also found low self-reported compliance on seat belt use as a passenger $(43 \%)$. This is significantly lower than the finding reported by Jamjute et al. which was $78.5 \%{ }^{14}$

One of the potential reasons that contributed to the wide range of compliance on seat belt use among pregnant women is the difference in national legislation between countries and its enforcement. Ichikawa et al. found a similar compliance rate of $42 \%$. They also found that there was a reduction in compliance of using seat belt during pregnancy from before pregnancy among the studied group. ${ }^{17}$ The pertinent similarity that may explain the similarly low compliance rate was that our local legislators are similar in term of there is flexibility given to pregnant women to be exempt from wearing a seat belt. This is further supported by a report from Center for Disease Control in the United States that the prevalence of wearing a seat belt is $85 \%$, and it is lower in states without law enforcement measures. ${ }^{18}$

Another factor that may contribute to the varying compliance rate is the education level. It has been found to be a predictor for seat belt use, with the high school graduate more likely to use seat belt than those who received less than a high school education. ${ }^{15}$ This pattern was also found in a study by Taylor et al. when comparing pregnant women in a county clinic that were generally less educated against a group of pregnant women that were generally more educated attending private practice clinic. The compliance rate is $49 \%$ and $83 \%$, respectively. ${ }^{16}$ Interestingly, despite having a majority $(76.3 \%)$ of women in our study with tertiary education level, the compliance rate remained low. Therefore, education level alone may not be a good predictor for compliance on seat belt use in pregnancy in our population.

Similar with the previous studies, ${ }^{2,15,17,19}$ the main reason given for noncompliance on the seat belt use in this study was that the women felt uncomfortable wearing it. The other reason given was they felt that seat belt use was unnecessary for short trips. Looking at all the reasons given, it is clear that if the women are given adequate knowledge on the importance, benefits and the correct way of using seat belt during pregnancy, their compliance will improve. In other studies, reasons given for noncompliance include fear of harming the fetus and knowing that pregnant women were exempted from seat belt use ${ }_{1}^{17}$ which we did not find in our study. We have no clear explanation for this.

Our study also found there were only 20 (25\%) women who knew the correct way of using a seat belt in pregnancy. This is lower compared to previously reported in other studies of between $47-83 \% .{ }^{2,15,17,19}$ This is worrying as it indicated a significant number of pregnant women wearing seat belt did not wear it properly. Hence, it can cause more harm to the fetus and the pregnant women themselves if they become involved with a road traffic accident.

The previous study has found a significant positive association incorrect placement of the seat belt between those that recalled receiving advice or information. ${ }^{15} \mathrm{As}$ our study only found $20(25 \%)$ women received information pertaining to seat belt use in pregnancy, then it is not surprising that the knowledge and understanding of the correct placement of seat belt in pregnancy are low. This is comparable with results from previous studies that reported only $22-28 \%$ of women received advice on this. ${ }^{14,16}$ Some women obtained the informa- 
tion from more than one source. Unfortunately, in this study, only $12.1 \%$ received information from healthcare personnel such as doctors or nurses, who were supposed to be the most reliable source of information. Regular contact during routine antenatal visits between healthcare professionals and pregnant women should be the best opportunity to educate them on correct seat belt use in pregnancy. Healthcare professionals must take important role and responsibilities in imparting crucial information pertaining seat belt use to the antenatal women. Further, education for the general public should also be emphasized, as it was shown that those women who always wear a seat belt before pregnancy would continue to do so when they are pregnant. ${ }^{20}$ However, education during pregnancy remained essential, as there are differences in the positioning of the seat belt during pregnancy.

It is crucial to further investigate the underlying cause of failure in the provision of accurate information on this important subject during antenatal care. It is of concern when Jamjute et al. reported that $16 \%$ of health professional indicated a wrong seat belt position. ${ }^{14}$ Therefore studies on knowledge and awareness among healthcare professionals and the challenges to impart education on seat belt use in pregnancy during antenatal care should be carried out in future. This will guide further effective intervention to improve women's knowledge on this essential safety issue.

The positive impact on the practice of seat belt use in pregnancy after appropriate information has been imparted has been proven in previous studies. ${ }^{15,21}$

Therefore a combined effort from all parties including media and nongovernmental organizations, in putting effort to diversify the sources of information and public health campaign on seat belt use in pregnancy is vital to ensure more women will be aware and receive the correct information.

Limitation of our study is that we relied on the self-reporting of the wearing of seat belt rather than observed the actual practice which may cause reporting bias, as it was shown that there is a discrepancy between the actual practices when compared to the reported practice. $^{22}$

\section{CONCLUSION}

There is lacking in awareness on the importance and correct seat belt use in pregnancy among the pregnant women. A serious effort should be made on empowering women with adequate knowledge that hopefully will improve their compliance and subsequently will reduce preventable maternal death due to a motor vehicle accident.

\section{CLINICAL SIGNIFICANCE}

Our study showed that there is a need to educate the use of seat belt among pregnant women to reduce the harm caused from noncompliance and incorrect usage.

\section{ACKNOWLEDGMENTS}

Authors would like to acknowledge Universiti Tekologi MARA for the research grant 600-IRMI/Dana 5/3/ LESTARI(0085/2016). In addition, the authors would like to thank Wan Hamizan Wan Zainudin, Aisyah Ahmad Zubaidi, Maryam Nabilah Mustaffa, Airin Zainudin and Nur Sofia Hamzah for helping with data collection.

\section{REFERENCES}

1. Hitosugi M, Motozawa $Y$, et al. Traffic injuries of the pregnant women and fetal or neonatal outcomes. Forensic Sci Int 2006;159:51-54.

2. Azar T, Longo C, et al. Motor vehicle collision-related accidents in pregnancy. J Obstet Gynaecol Res 2015;41: 1370-1376.

3. Hyde LK, Cook LJ, et al. Effect of motor vehicle crashes on adverse fetal outcomes. Obstet Gynecol 2003;102: 279-286.

4. Crosby WM, Costiloe JP. Safety of lap-belt restraint for pregnant victims of automobile collisions. N Engl J Med 1971;284: 632-636.

5. Hendey GW, Votey SR. Injuries in restrained motor vehicle accident victims. Ann Emerg Med 1994;24:77-84.

6. Weiss HB, Songer TJ, et al. Fetal deaths related to maternal injury. JAMA 2001;286:1863-1868.

7. Pearlman MD, Tintinalli JE, et al. Blunt trauma during pregnancy. N Engl J Med 1990;323:1609-1613.

8. Klinich KD, Flannagan CA, et al. Fetal outcome in motorvehicle crashes: effects of crash characteristics and maternal restraint. Am J Obstet Gynecol 2008;198:450 e1-9.

9. Crosby WM, King AI, et al. Fetal survival following impact: improvement with shoulder harness restraint. Am J Obstet Gynecol 1972;112:1101-1106.

10. Astarita DC, Feldman B. Seat belt placement resulting in uterine rupture. The Journal of trauma 1997;42:738-740.

11. Kvarnstrand L, Milsom I, et al. Maternal fatalities, fetal and neonatal deaths related to motor vehicle crashes during pregnancy: a national population-based study. Acta Obstet Gynecol Scand 2008;87:946-952.

12. Hammond TL, Mickens-Powers BF, et al. The use of automobile safety restraint systems during pregnancy. J Obstet Gynecol Neonatal Nurs 1990;19:339-343.

13. Acar BS WA. Pregnant driver behaviour and safety. First International Coference on Driver Behaviour and Training 2003;1.

14. Jamjute P, Eedarapalli P, et al. Awareness of correct use of a seatbelt among pregnant women and health professionals: a multicentric survey. J Obstet Gynaecol 2005;25:550-553.

15. Johnson HC, Pring DW. Car seatbelts in pregnancy: the practice and knowledge of pregnant women remain causes for concern. BJOG 2000;107:644-647.

16. Taylor AJ, McGwin G Jr, et al. Seatbelt use during pregnancy: a comparison of women in two prenatal care settings. Matern Child Health J 2005;9:173-179. 
17. Ichikawa M, Nakahara S, et al. Car seatbelt use during pregnancy in Japan: determinants and policy implications. Inj Prev 2003;9:169-172.

18. Centers for Disease C, Prevention. Vital signs: Nonfatal, motor vehicle-occupant injuries (2009) and seat belt use (2008) among adults- United States. MMWR Morb Mortal Wkly Rep 2011;59:1681-1686.

19. Pearlman MD, Phillips ME. Safety belt use during pregnancy. Obstet Gynecol 1996;88:1026-1029.
20. Tyroch AH, Kaups KL, et al. Pregnant women and car restraints: beliefs and practices. J Trauma 1999;46:241-245.

21. McGwin G, Jr. Russell SR, et al. Knowledge, beliefs, and practices concerning seat belt use during pregnancy. J Trauma 2004;56:670-675.

22. Streff FM, Wagenaar AC. Are there really shortcuts? Estimating seat belt use with self-report measures. Accid Anal Prev 1989;21: 509-516. 